\title{
The Effect of Carbonates and Silicates on the Cracking of a Mixture of Fuel Oil and Mechanically Activated Oil Shale
}

\author{
Marina V. Mozhayskaya*, \\ Galina S. Pevneva and Vladimir G. Surkov \\ Institute of Petroleum Chemistry SB RAS \\ Tomsk, Russian Federation
}

Received 10.04.2021, received in revised form 12.05.2021, accepted 06.06.2021

\begin{abstract}
The study cracking of a mixture of mechanically activated oil shale (MO OSh) and fuel oil, a mixture of demineralized MO GS and fuel oil has been investigated. The data on the composition of liquid products showed that after the removal of mineral components, oil shale is more easily destroyed due to the release of kerogen. It is shown that in the obtained liquid products of the cracking of the mixture of fuel oil - demineralized MO OSh, the proportion of oils increases to $74.6 \% \mathrm{wt}$. In the composition of gaseous products of cracking, the amount of hydrogen, methane and ethane is noticeably reduced. According to the data on the fractional composition of liquid products, it was found that during the cracking of mixtures of fuel oil and MO HS, after the removal of carbonates and silicates, the proportion of gasoline and diesel fractions increases.
\end{abstract}

Keywords: carbonates, silicates, mechanically activated oil shale, fuel oil, composition, cracking. 


\title{
Влияние карбонатов и силикатов \\ на крекинг смеси мазута \\ и механоактивированного горючего сланца
}

\author{
М.В. Можайская, \\ Г. С. Певнева, В. Г. Сурков \\ Институт химии нефти СО РАН \\ Российская Федерации, Томск
}

\begin{abstract}
Аннотация. Исследован совместный крекинг смеси механоактивированного горючего сланца (МО ГС) и мазута, смеси деминерализованного МО ГС и мазута. Данные по составу жидких продуктов показали, что после удаления минеральных компонентов горючий сланец легче подвергается разрушению за счет высвобождения керогена. Показано, что в полученных жидких продуктах крекинга смеси мазут - деминерализованный МО ГС доля масел увеличивается до 74,6 \% мас. В составе газообразных продуктов крекинга заметно снижается количество водорода, метана и этана. По данным фракционного состава жидких продуктов установлено, что при крекинге смесей мазута и МО ГС после удаления карбонатов и силикатов увеличивается доля бензиновых и дизельных фракций.
\end{abstract}

Ключевые слова: карбонаты, силикаты, механоактивированный горючий сланец, мазут, состав, крекинг.

Цитирование: Можайская, М.В. Влияние карбонатов и силикатов на крекинг смеси мазута и механоактивированного горючего сланца / М. В. Можайская, Г. С. Певнева, В. Г. Сурков // Журн. Сиб. федер. ун-та. Химия, 2021, 14(2). С. $234-241$. DOI: $10.17516 / 1998-2836-0232$

\section{Введение}

В настоящее время в связи с истощением запасов легких нефтей большое внимание уделяется разработке и внедрению технологий глубокой переработки тяжелого углеводородного сырья. Помимо тяжелых нефтей и нефтяных остатков в качестве альтернативы ресурсов легких и средних нефтей для получения моторных топлив рассматриваются природные битумы, бурые угли и горючие сланцы [1-7].

В настоящее время существуют способы получения синтетической нефти из ГС, которые в основном заключаются в использовании методов термической переработки ГС. Основными продуктами, получаемыми такими способами, являются сланцевый газ и жидкие углеводородные компоненты $[3,5]$. На выход и состав продуктов термической переработки ГС может влиять как состав исходного сланца, температура, продолжительность процесса, так и степень измельчения сланцевой породы [8].

В связи с увеличением доли тяжелых нефтей и поступающих на переработку нефтяных остатков растет потребность совершенствования существующих и разработка новых методов увеличения глубины их переработки. Совместный крекинг нефтяных остатков и ГС может позволить 
интенсифицировать процесс деструкции высокомолекулярных компонентов мазута, что приводит к увеличению выхода компонентов моторных топлив [9].

Минеральная составляющая ГС также может оказывать влияние на процесс термокрекинга тяжелых нефтяных остатков, так как в ее состав входят алюмосиликатные компоненты и соли железа [10-12], которые могут выступать в роли активирующих каталитических добавок [9].

В литературе известны примеры использования совместного крекинга мазута и гудрона в присутствии как органоминеральных активаторов, так и цеолитов [13]. Этот процесс является термокаталитическим, протекающим в сравнительно мягких условиях (415-425 $\left.{ }^{\circ} \mathrm{C}\right)$, при этом добавки горючего сланца (10-12 \% мас.) могут выступать в роли как катализатора процесса, так и адсорбента кокса. При таких условиях из мазута и гудрона могут быть получены фракции светлых нефтепродуктов (автомобильные бензины и дизельные топлива) с выходом до $60 \%$ мас.

Показано, что совместный крекинг механообработанного (МО) ГС и мазута в среде воды приводит к более глубокой деструкции высокомолекулярных компонентов нефтяного остатка [14]. Сланец в данном случае может выступать как активирующая добавка, которая инициирует деструкцию компонентов мазута $[11,12]$.

Результаты исследований по разработке процесса термического крекинга гудрона в виде суспензии с измельченным прибалтийским горючим сланцем с целью получения компонентов моторных топлив свидетельствуют о несомненных преимуществах процесса перед промышленным термокрекингом гудрона [15]. Так, при одноступенчатой схеме переработки сырья в относительно мягких условиях (5 Мпа, $425{ }^{\circ} \mathrm{C}$, объемная скорость подачи сырья 1.0 ч $^{-1}$ ) достигается глубокая деструкция. В расчете на исходный гудрон выход бензиновой фракции составляет около $12 \%$ мас., средних дистиллятов - $43 \%$ мас.

Ранее нами были проведены работы по изучению совместного крекинга механоактивированного горючего сланца (МО ГС) и мазута [16]. Введение МО горючего сланца в качестве активирующей добавки позволило интенсифицировать процесс деструкции высокомолекулярных компонентов мазута и привело к качественному изменению фракционного состава жидких продуктов крекинга (увеличился выход жидких и дизельных фракций).

В данной работе изучено влияние карбонатов и силикатов МО горючего сланца на термические превращения мазута с целью получения компонентов моторных топлив.

\section{Объекты и методы исследования}

Объектами исследования являются горючий сланец месторождения «Тухурмийн Нуур» (Монголия) и мазут тяжелой нефти месторождения «Зуунбаян» (Монголия) с высоким содержанием смол. Физико-химические свойства ГС представлены в табл. 1. Выделение битумоида и керогена, элементный анализ проводили по методикам [17].

Мазут зуунбаянской нефти характеризуется низким содержанием асфальтенов $(0,4 \%$ мас.) и серы (0,1 \% мас.), но при этом содержит 25,5 \% смол и 15,7 \% мас. твердых парафинов, плотность мазута составляет 895,2 кг/ $\mathrm{M}^{3}$, температура застывания $63{ }^{\circ} \mathrm{C}$.

Сланец измельчали на установке АГО - $2 \mathrm{M}$ при скорости вращения реакторов 2220 об/мин, в течение 10 минут, в среде аргона. При использовании планетарных шаровых 
Таблица 1. Физико-химические характеристики горючего сланца

Table 1. Physicochemical characteristics of oil shale

\begin{tabular}{|c|c|c|}
\hline \multicolumn{2}{|c|}{ Показатели } & Содержание, \% мас. \\
\hline \multicolumn{2}{|c|}{ Влажность, мас. \% } & 2,1 \\
\hline \multicolumn{2}{|c|}{ Зольность общая, мас. \% } & 83,20 \\
\hline \multicolumn{2}{|c|}{ Выход летучих продуктов, мас. \% } & 14,75 \\
\hline Минеральная часть & $\begin{array}{c}\text { Карбонаты } \\
\text { Силикаты }\end{array}$ & $\begin{array}{l}27,4 \\
56,2\end{array}$ \\
\hline Органическая часть & $\begin{array}{c}\text { Кероген } \\
\text { Битумоид }\end{array}$ & $\begin{array}{l}13,8 \\
0,49\end{array}$ \\
\hline Элементный состав керогена & $\begin{array}{c}\mathrm{C} \\
\mathrm{H} \\
\mathrm{S} \\
\mathrm{N} \\
\mathrm{O}\end{array}$ & $\begin{array}{c}70,1 \\
13,4 \\
2,1 \\
3,2 \\
11,2\end{array}$ \\
\hline
\end{tabular}

мельниц параллельно с измельчением минеральной части происходит частичная деструкция органической части сланца. После МО ГС просеивали и отбирали фракцию менее 50 мкм. МО горючий сланец подвергали дебитуминизации и деминерализации по методикам [17]. При обработке концентрированной соляной кислотой МО горючего сланца было достигнута полная декарбонизация. Последующая обработка плавиковой кислотой приводит к удалению большей части содержащихся в сланце силикатов (49,5 \% мас.). Следует учитывать, что небольшое количество силикатов (6,7 \% мас.), оставшихся после обработки МО ГС плавиковой кислотой, возможно, будет играть роль каталитической добавки при деструкции как мазута, так и керогена МО ГС.

Смеси мазута и МО горючего сланца готовили в соотношении 80:20, которое выбрано по результатам работы [16].

Термолиз проводили в герметичном реакторе из нержавеющей стали в среде аргона при температуре $435{ }^{\circ} \mathrm{C}$ в течение 60 минут. Газ после крекинга отбирали в пробоотборник объемом 0,5 л через гидрозатвор (регистрируя объем отобранного газа и его массу). Разделение жидких продуктов на масла, смолы и асфальтены осуществляли по методике [18].

\section{Результаты экспериментов и их обсуждение}

Для исследования были приготовлены три смеси мазута и горючего сланца:

1) мазут и МО ГС; 2) мазут и МО ГС после удаления карбонатов; 3) мазут и МО ГС после удаления карбонатов и силикатов (деминерализованный).

В табл. 2 представлен материальный баланс крекинга смесей мазута и МО ГС. Данные материального баланса свидетельствуют о том, что в отсутствие карбонатов выход жидких продуктов увеличивается до 76,3% мас., а для смеси мазут - деминерализованный МО ГС увеличивается до 84,3 \% мас. (табл. 2). Снижение количества минеральных компонентов ГС в реакционной смеси приводит к снижению выхода твердых продуктов. Под твердыми продуктами подразумевается непрореагировавшая минеральная часть горючего сланца и образу-

$$
-237-
$$


Таблица 2. Материальный баланс продуктов крекинга смесей мазут - МО ГС

Table 2. Material balance of cracked fuel oil mixtures MO - OSh

\begin{tabular}{|c|c|c|c|}
\hline \multirow{2}{*}{ Продукты } & \multicolumn{3}{|c|}{ Выход продуктов, \% мас. } \\
\cline { 2 - 4 } & Мазут - МО ГС & $\begin{array}{c}\text { Мазут - МО ГС } \\
\text { без карбонатов }\end{array}$ & $\begin{array}{c}\text { Мазут - } \\
\text { деминерализованный } \\
\text { МО ГС }\end{array}$ \\
\hline Газообразные & 5,3 & 3,2 & 3,0 \\
Твердые & 20,9 & 20,5 & 12,7 \\
Жидкие & 73,8 & 76,3 & 84,3 \\
\hline
\end{tabular}

ющиеся в процессе крекинга коксоподобные вещества, разделить которые не представляется возможным.

Количество образующихся газов после крекинга смеси мазут - МО ГС составляет 5,3 \% мас., в смесях мазут - МО ГС без карбонатов и мазут - деминерализованный МО ГС количество образующихся газов снижается в 1,7-1,8 раза. Газообразные продукты всех смесей мазута с горючим сланцем имеют одинаковый состав из водорода, углекислого газа, азота, окислов углерода и углеводородов (табл. 3). При крекинге смесей мазут - МО ГС без карбонатов и мазут - деминерализованный МО ГС содержание водорода снижается почти в 2 раза по сравнению с газами смеси мазут - исходный МО ГС. Содержание двуокиси углерода в газообразных продуктах крекинга свидетельствует о протекании реакций декарбоксилирования и декарбонилирования органических соединений. После удаления карбонатов и силикатов из МО ГС происходит снижение содержания $\mathrm{CO}_{2}$ в продуктах крекинга. Удаление минеральной части сланца приводит к снижению содержания метана, эта-

Таблица 3. Состав газообразных продуктов крекинга

Table 3. Composition of gaseous products of cracking

\begin{tabular}{|c|c|c|c|}
\hline \multirow[b]{2}{*}{ Компоненты газов } & \multicolumn{3}{|c|}{ Содержание газов, \% мас. } \\
\hline & Мазут - МО ГС & $\begin{array}{c}\text { Мазут - МО ГС } \\
\text { без карбонатов }\end{array}$ & $\begin{array}{c}\text { Мазут - } \\
\text { деминерализованный } \\
\text { МО ГС }\end{array}$ \\
\hline $\mathrm{H}_{2}$ & 0,28 & 0,12 & 0,17 \\
\hline $\mathrm{CH}_{4}$ & 2,28 & 1,55 & 1,86 \\
\hline $\mathrm{CO}_{2}$ & 0,13 & 0,10 & 0,11 \\
\hline $\mathrm{C}_{2} \mathrm{H}_{4}$ & 0,05 & 0,03 & 0,04 \\
\hline $\mathrm{C}_{2} \mathrm{H}_{6}$ & 1,07 & 0,59 & 0,32 \\
\hline $\mathrm{C}_{3} \mathrm{H}_{6}$ & 0,10 & 0,04 & 0,04 \\
\hline $\mathrm{C}_{3} \mathrm{H}_{8}$ & 0,80 & 0,39 & 0,08 \\
\hline i $\mathrm{C}_{4} \mathrm{H}_{10}$ & 0,07 & 0,03 & 0,03 \\
\hline $\mathrm{n} \mathrm{C}_{4} \mathrm{H}_{10}$ & 0,25 & 0,07 & 0,09 \\
\hline $\mathrm{C}_{4} \mathrm{H}_{8}$ & 0,05 & 0,01 & 0,02 \\
\hline $\mathrm{C}_{5} \mathrm{H}_{10}$ & 0,0001 & 0,0006 & 0,0008 \\
\hline Алканы $>\mathrm{C}_{5}$ & 0,11 & 0,01 & 0,02 \\
\hline $\mathrm{CO}$ & 0,05 & 0,06 & 0,08 \\
\hline $\mathrm{N}_{2}$ & 0,07 & 0,19 & 0,14 \\
\hline
\end{tabular}


на, пропана и пропилена. Значительного изменения содержания этилена в составе газов не наблюдается.

Проведенный анализ жидких продуктов крекинга показал, что после удаления из сланца минеральной части наблюдается увеличение количества и улучшение качества жидких продуктов. Это происходит за счет того, что после удаления из ГС минеральной части кероген становится более доступным и легче подвергается деструкции в процессе крекинга.

Данные вещественного состава показали, что в жидких продуктах крекинга смесей мазут - МО ГС в отсутствие карбонатов и мазут - деминерализованный МО ГС выход масел увеличивается до 66,9 и 74,6 \% мас. соответственно (табл. 4). Содержание смол и асфальтенов в смесях мазут - МО ГС после удаления карбонатов и силикатов изменяется незначительно.

Фракционный состав жидких продуктов крекинга был определен на основе данных термогравиметрического анализа. На рис. 1 видно, что удаление карбонатов из МО ГС не повлияло на выход бензиновых фракций (НК-200 $\left.{ }^{\circ} \mathrm{C}\right)$ жидких продуктов крекинга, однако в них существенно увеличилось содержание дизельной фракции (200-360 $\left.{ }^{\circ} \mathrm{C}\right)$. В отсутствие и карбонатов, и силикатов в МО ГС в жидких продуктах крекинга смеси доля бензиновой фракции увеличивается в 1,4 раза по сравнению с остальными образцами (рис. 1).

Таблица 4. Вещественный состав жидких продуктов крекинга

Table 4. The component composition of liquid products of cracking

\begin{tabular}{|c|c|c|c|}
\hline \multirow{2}{*}{$\begin{array}{c}\text { Компоненты жидких } \\
\text { продуктов }\end{array}$} & \multicolumn{3}{|c|}{ Смеси мазут - ГС, \% мас. } \\
\cline { 2 - 4 } & Мазут - МО ГС & $\begin{array}{c}\text { Мазут - МО ГС } \\
\text { без карбонатов }\end{array}$ & $\begin{array}{c}\text { Мазут - } \\
\text { деминерализованный } \\
\text { МО ГС }\end{array}$ \\
\hline Смолы & 6,0 & 6,7 & 6,8 \\
Асфальтены & 2,7 & 2,7 & 2,9 \\
Масла & 64,3 & 66,9 & 74,6 \\
\hline
\end{tabular}

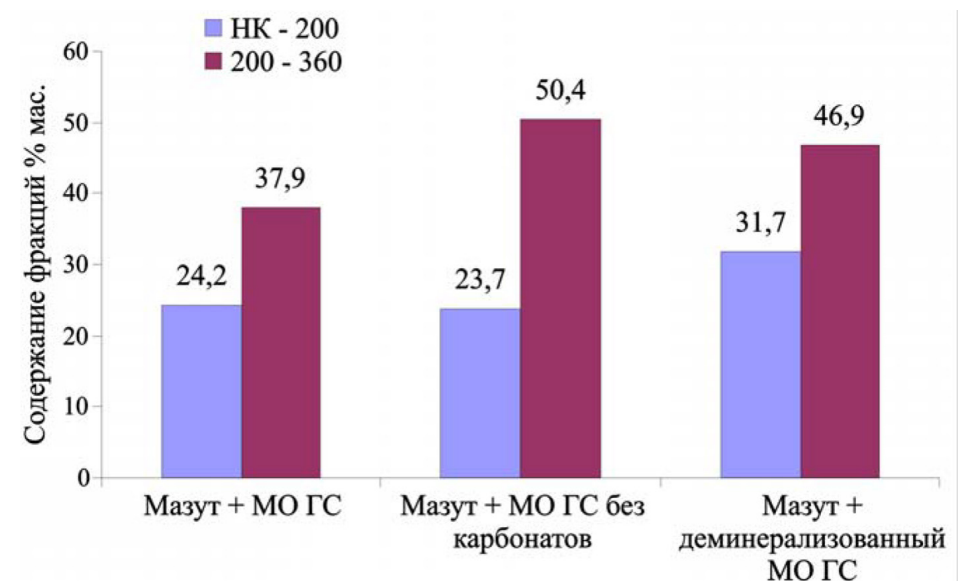

Рис. 1. Фракционный состав жидких продуктов крекинга смесей мазут - МО ГС

Fig. 1. Fractional composition of liquid products of cracking of mixtures fuel oil - MO OSh

$$
-239-
$$




\section{Заключение}

Таким образом, в результате проделанной работы показано, что при крекинге смесей мазут - МО ГС в отсутствие карбонатов и мазут - МО ГС после удаления карбонатов и силикатов значительно снижается количество газообразных и твердых продуктов, выход жидких продуктов увеличивается. В составе газообразных продуктов крекинга смесей мазут - МО ГС без карбонатов и мазут - деминерализованный МО ГС значительно снижается количество водорода, метана, этана, пропана и пропилена. Показано, что удаление карбонатов и силикатов из МО ГС приводит к увеличению содержания масел в жидких продуктах крекинга, количество смол и асфальтенов изменяется незначительно.

Фракционный состав жидких продуктов термолиза показал, что при крекинге смесей мазут - МО ГС в отсутствие карбонатов и мазут - МО ГС без карбонатов и силикатов увеличивается доля дизельных фракций в 1,3 раза. Деминерализация МО ГС приводит к увеличению в составе жидких продуктов термолиза содержания бензиновой фракции в 1,4 раза по сравнению с остальными изученными образцами.

\section{Благодарности / Acknowledgments}

Работа выполнена в рамках государственного задания ИХН СО РАН, финансируемого Министерством науки и высшего образования Российской Федерации.

This work was supported by the Ministry of Science and Higher Education of the Russian Federation.

\section{Список литературы / References}

1. Kang Z., Zhao Y., Yang D. Review of oil shale in-situ conversion technology. Applied Energy 2020. Vol. 269, P. 115121.

2. Lu Y., Wang Y., Zhang J., Wang Q., Zhao Y., Zhang Y. Investigation on the characteristics of pyrolysates during co-pyrolysis of Zhundong coal and Changji oil shale and its kinetics. Energy 2020, P. 117529.

3. Ma Y., Li S. The mechanism and kinetics of oil shale pyrolysis in the presence of water. Carbon Resources Conversion 2018. Vol . 1. №. 2, P. 160-164.

4. Mu M., Han X., Jiang X. Interactions between oil shale and hydrogen-rich wastes during copyrolysis: 1. Co-pyrolysis of oil shale and polyolefins. Fuel 2020. Vol. 265, P. 116994.

5. Lu Y. et al. Investigation on the catalytic effect of AAEMs on the pyrolysis characteristics of Changji oil shale and its kinetics. Fuel 2020. Vol. 267, P. 117287.

6 Kopytov M.A., Golovko A.K., Kirik N.P., Anshits A.G. Combined cracking of brown coal and petroleum residue in the presence of initiating additives. Solid Fuel Chemistry 2013. Vol. 47(2), P. 114-119.

7. Shar A.M., Mahesar A.A., Memon K.R. Could shale gas meet energy deficit: its current status and future prospects. Journal of Petroleum Exploration and Production Technology 2017, P. 1-11.

8. Shawabkeh A.Q., Abdulaziz M. Shale hold time for optimum oil shale retorting inside a batchloaded fluidized-bed reactor. Oil Shale 2013. Vol. 30(2), P. 173-183.

9. Hosseinpour M., Fatemi S., Ahmadi S.J. Catalytic cracking of petroleum vacuum residue in supercritical water media: Impact of $\alpha-\mathrm{Fe}_{2} \mathrm{O}_{3}$ in the form of free nanoparticles and silica-supported granules. Fuel 2015. Vol. 159, P. 538-549. 
10. Lee S. Oil shale technology. CRC Press, 1990. 280 p.

11. Кривонос О.И., Терехова Е.Н., Галдина В.Д., Плаксин Г.В. Исследование минеральных компонентов горючих сланцев и их углеродминеральных остатков при термолизе. Известия высших учебных заведений. Серия: Химия и химическая технология 2015. Т. 58(3), С. 69-73. [Krivonos O.I, Terekhova E.N., Galdina V.D., Plaksin G.V. Investigation of the mineral components of combustible shale and their carbon-mineral residues during thermolysis. Proceedings of higher educational institutions. Series: Chemistry and Chemical Technology 2015. Vol. 58 (3), P. 69-73. (In Russ.)]

12. Nazarenko M.Y., Kondrasheva N.K., Saltykova S.N. Surface reactivity of fuel shales from the Baltic basin. Coke and Chemistry 2016. Vol. 59(5), P. 196-199.

13. Горлов Е.Г., Котова А.С., Горлова Е.Е. Термокаталитическая переработка нефтяных остатков в присутствии цеолитов и горючих сланцев. Химия твердого топлива. 2009. № 1 , C. 31-38. [Gorlov E.G., Kotova A.S., Gorlova E.E. Thermocatalytic processing of oil residues in the presence of zeolites and oil shale. Solid fuel chemistry 2009. № 1, C. 31-38. (In Russ.)]

14. Савельев В.В., Головко А.К., Камьянов В.Ф. Влияние условий предварительной механоактивации горючих сланцев на выход и состав продуктов при термолизе в среде воды. Известия Томского политехнического университета 2013. Т. 323(3), C. 52-58. [Saveliev V.V., Golovko A.K., Kamyanov V.F. Influence of the conditions of preliminary mechanical activation of combustible shale on the yield and composition of products during thermolysis in a water environment. Bulletin of Tomsk Polytechnic University 2013. Vol. 323(3), P. 52-58. (In Russ.)]

15. Maloletnev A.S., Yulin M.K., Vol'-Apshtein A.B. Thermal cracking of heavy oil residues mixed with shale. Solid fuel chemistry 2011. Vol. 45. № 4, P. 233-238.

16. Можайская М.В., Сурков В.Г., Копытов М.А., Головко А.К. Совместный крекинг нефтяного остатка и механоактивированного горючего сланца. Журнал Сибирского федерального университета. Химия. 2019. Т. 12, № 3. C. 319-327 [Mozhayskaya M.V., Surkov V.G., Kopytov M.A., Golovko A.K. Combined Cracking Residue and Mechanical Activation Oil Shale. Journal of the Siberian Federal University. Chemistry 2019. Vol. 12, № 3, P. 319-327. (In Russ.)]

17. Saveliev V.V., Pevneva G.S., Namkhainorov Zh., Golovko A.K. Oil shale of Mongolia. Solid fuel chemistry 2011. Vol. 45. № 6, P. 397-403.

18. Pevneva G.S., Voronetskaya N.G., Grin'ko A.A., Golovko A.K. Influence of resins and asphaltenes on thermal transformation of hydrocarbons of paraffine-base heavy oil. Petroleum Chemistry 2016. Vol. 56. № 8, P. 690-696. 